\title{
DOSES E FORMAS DE APLICAÇÃO DE POTÁSSIO NA CULTURA DO FEIJOEIRO EM SISTEMA DE PLANTIO DIRETO NA PALHA
}

\author{
POTASSIUM DOSES AND APLICATION FORNS IN COMMON \\ BEANS IN NO TILLAGE SYSTEM
}

\author{
José Carlos SGUARIO-JR. ${ }^{1}$ \\ Edelclaiton DAROS ${ }^{2}$ \\ Volnei PAULETTI ${ }^{3}$ \\ Pedro RONZELLI-JR. ${ }^{2}$ \\ Henrique SOARES-KOEHLER ${ }^{4}$ \\ Ricardo Augusto de OLIVEIRA ${ }^{5}$
}

\section{RESUMO}

Em 1997/98 e 1998/99 foram implantados experimentos de campo em Tibagi, PR, com o objetivo de avaliar a resposta da cultura do feijão, cultivar Carioca a diferentes doses de potássio (0,30,60, 90 e $120 \mathrm{~kg} \mathrm{ha}^{-1}$ de $\left.\mathrm{K}_{2} \mathrm{O}\right)$ e em duas formas de aplicação (linha e lanço) em sistema de plantio direto na palha. O delineamento experimental foi o de blocos ao acaso em arranjo fatorial $2 \times 5 \mathrm{em}$ quatro repetições. Nos estádios $R_{5}, R_{6}, R_{7}, R_{8}$ e $R_{9}$ foram amostradas dez plantas para avaliação da massa seca. Foram coletadas folhas de vinte plantas para ser observado o teor de potássio no tecido foliar. Nos dois anos de avaliação a cultura não respondeu a diferentes doses de potássio e às formas de aplicação para o rendimento e seus componentes, mostrando que mesmo para altas produtividades e com as condições climáticas favoráveis a reserva do solo supriu a sua necessidade da planta deste elemento, que foi formada pela constante reposição dos restos culturais das culturas antecessoras.

Palavras-chave: Phaseolus vulgaris, plantio direto, potássio.

\begin{abstract}
In 1997/98 and 1998/99 experiments were implanted in field in Tibagi, PR, to evaluate the answer of the common beans at the different potassium rates $\left(0,30,60,90\right.$ and $120 \mathrm{~kg} \mathrm{ha}^{-1}$ of $\left.\mathrm{K}_{2} \mathrm{O}\right)$ and two application forms (line and throw), in Cultivar Carioca in notill system. The experiment was installed in randomized blocks in arrangement factorial $2 \times 5$ with four replications. In the stages $R_{5}, R_{6}$, $R_{7}, R_{8}$ e $R_{9}$ they were used ten plants and evaluated dry mass. The leaves of twenty plants were collected to observe the potassium level in the leaf tissue. In the two years of evaluation, the culture didn't answer to the different potassium doses and the two application forms to the yield and its components, showing that, even for high yields, favorable climatic conditions, the plant supplies its need for the element in the soil, due constant replacement of the cultures predecessors, cultural remains.
\end{abstract}

Key-words: Phaseolus vulgaris, no tillage, potassium.

\footnotetext{
${ }^{1}$ Engenheiro Agrônomo, aluno do Curso de Pós Graduação, Produção Vegetal, UFPR. Avenida dos Pioneiros, 2324, CEP 84145-000, Carambeí, PR. <zezo@convoy.com.br> autor para correspondência.

${ }^{2}$ Engenheiro Agrônomo, Doutor, Universidade Federal do Paraná, Professor Adjunto.

${ }^{3}$ Engenheiro Agrônomo M.Sc., Doutorando em Agronomia, Produção Vegetal, UFPR e Pesquisador da Fundação ABC.

${ }^{4}$ Engenheiro Florestal, Doutor, Universidade Federal do Paraná, Professor Adjunto.

${ }^{5}$ Engenheiro Agrônomo, M.Sc., Doutorando em Agronomia, Produção Vegetal, UFPR.
} 


\section{INTRODUÇÃO}

O feijoeiro (Phaseolus vulgaris) tem um importante papel na alimentação da população brasileira, em função do seu alto valor protéico (22$26 \%$ ), substituindo assim a proteína animal, que apresenta alto custo e não está ao alcance da população de baixa renda [4]. Além da alimentação, a cultura se destaca pela alta rentabilidade obtida pelos agricultores, que investem em tecnologia e aplicação de insumos de maneira adequada [6].

A região dos Campos Gerais do Paraná se destaca pelo cultivo das suas áreas em sistema de plantio direto na palha. A fertilidade destes solos cultivados sob plantio direto, apresenta efeitos residuais culturais com o acúmulo de nutrientes nas camadas superficiais, podendo favorecer as culturas em sucessão [11, 12, 17, 16].

A cultura do feijoeiro pode ser influenciada por vários fatores, como a forma de distribuir o adubo e respectiva dose, pois Kluthcoushi [9] relata que pode haver um efeito prejudicial no rendimento da cultura, pois fertilizantes salinos como os potássicos podem causar injúrias às plântulas, podendo reduzir em até $50 \%$ a população final de plantas de feijoeiro. Pauletti [14] relata que o feijoeiro pode extrair do solo em média $93 \mathrm{~kg} \mathrm{~T}^{-1}$ de $\mathrm{K}_{2} \mathrm{O}$ pela planta e exporta na ocasião da colheita $15,4 \mathrm{~kg} \mathrm{~T}^{-1}$ de $\mathrm{K}_{2} \mathrm{O}$ pelas sementes. Outro fator que pode influenciar o rendimento do feijoeiro é o efeito do ano agrícola e do ambiente, pois muitas vezes é maior do que a resposta aos tratamentos com fertilizantes, indicando que estes ensaios devem ser repetidos em anos agrícolas [10].

O objetivo deste trabalho foi avaliar as diferentes doses de potássio e a sua forma de aplicação para a cultura do feijoeiro, em área de plantio direto na palha e em duas safras agrícolas, sendo avaliado o rendimento e seus componentes: a massa seca da planta, a altura da planta, população final e o teor de potássio nas folhas.

\section{MATERIAL E MÉTODOS}

Os experimentos foram conduzidos à campo, na Fazenda Santa Terezinha (1997/98), Tibagi, PR, em um Latossolo Vermelho Escuro Álico, em área de 12 anos de plantio direto na palha no dia 18/12 (Tabelas 1 e 3) e Fazenda Estiva (1998/99), Tibagi, PR, em um solo Podzólico Vermelho Amarelo Álico, em área de 13 anos de plantio direto na palha no dia 07/01 (Tabelas 2 e 4). O delineamento experimental empregado nos dois anos foi o de blocos ao acaso, com quatro repetições. Os dez tratamentos foram resultados do arranjo fatorial de duas formas de aplicação, na linha e a lanço, com cinco doses de adubação potássica $0,30,60,90$ e $120 \mathrm{~kg} \mathrm{ha}^{-1}$, na forma de cloreto de potássio. Todos os tratamentos receberam $25 \mathrm{~kg} \mathrm{ha}^{-1}$ de $\mathrm{N}$ e $40 \mathrm{~kg} \mathrm{ha}^{-1}$ de $\mathrm{P}_{2} \mathrm{O}_{5}$ no plantio e foi complementado com $45 \mathrm{~kg} \mathrm{ha}^{-1}$ de $\mathrm{N} \mathrm{em}$ cobertura no estádio de desenvolvimento $V_{3}$. A variedade utilizada foi a Carioca, Tipo III, hábito indeterminado, prostrado com ciclo médio de 90 dias [2]. O espaçamento usado foi de $0,45 \mathrm{~cm}$ entre fileiras, com sete metros de comprimento cada, perfazendo uma área total de $25,20 \mathrm{~m}^{2}$. Foram colhidas as duas linhas centrais da parcela desprezando-se $1 \mathrm{~m}$ à título de bordadura na frete e ao fundo de cada parcela, perfazendo uma área útil de $4,5 \mathrm{~m}^{2}$ para a avaliação do rendimento e seus componentes, população final e altura das plantas. Nos estádios $R_{5}, R_{6}, R_{7}, R_{8}$ e $R_{9}$ (Tabela 5), foram amostradas dez plantas ao acaso, cortadas rente ao solo para as avaliações de massa seca (MS) e para determinação do comprimento do caule, utilizando-se as fileiras laterais à parcela útil. Em cada tratamento foram coletadas aleatoriamente 3 folhas amadurecidas a partir do ápice, em 20 plantas, no início do florescimento $\left(R_{6}\right)$ para avaliar o teor de potássio nas folhas. Os resultados das avaliações foram submetidos à análise de variância e as médias comparadas pelo teste de Tukey, ao nível de 5\% de probabilidade utilizando o programa MSTATC [8].

TABELA 1 - Características químicas do solo da área experimental Fazenda Santa Terezinha, Tibagi, PR 1997.

\begin{tabular}{|c|c|c|c|c|c|c|c|c|c|c|c|}
\hline \multirow{2}{*}{ Profundidade } & $\mathrm{pH}$ & $\mathrm{Al}$ & $\mathrm{H}+\mathrm{Al}$ & $\mathrm{Ca}$ & $\mathrm{Mg}$ & $\mathrm{K}$ & $\mathrm{T}$ & \multirow{2}{*}{$\begin{array}{l}\text { P resina } \\
\mathrm{mg} \mathrm{dm}^{-3}\end{array}$} & \multirow{2}{*}{$\begin{array}{l}\text { M.O. } \\
\text { g. } \mathrm{dm}^{-3}\end{array}$} & $\mathrm{~V}$ & $\mathrm{Al}$ \\
\hline & $\mathrm{CaCl}_{2}$ & & & $\mathrm{mr}$ & $\mathrm{I}_{\mathrm{c}} \mathrm{dn}$ & & & & & \multicolumn{2}{|c|}{$\%$} \\
\hline $00-05$ & 5,7 & 0,0 & 33 & 64 & 37 & 5,10 & 138,6 & 125 & 49,0 & 76 & 0,0 \\
\hline $05-10$ & 5,5 & 0,0 & 38 & 53 & 34 & 4,25 & 128,8 & 80 & 44,0 & 71 & 0,0 \\
\hline $10-30$ & 4,8 & 2,1 & 64 & 26 & 18 & 2,60 & 110,1 & 26 & 44,0 & 42 & 4,4 \\
\hline
\end{tabular}

TABELA2 - Características químicas do solo da área experimental Fazenda Estiva, Tibagi, PR 1998.

\begin{tabular}{|c|c|c|c|c|c|c|c|c|c|c|c|}
\hline \multirow{2}{*}{ Profundidade } & $\mathrm{pH}$ & $\mathrm{Al}$ & $\mathrm{H}+\mathrm{Al}$ & $\mathrm{Ca}$ & $\mathrm{Mg}$ & $\mathrm{K}$ & $\mathrm{T}$ & \multirow{2}{*}{ 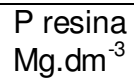 } & \multirow{2}{*}{$\begin{array}{l}\text { M.O. } \\
\text { g.dm }\end{array}$} & $\mathrm{V}$ & $\mathrm{Al}$ \\
\hline & $\mathrm{CaCl}_{2}$ & & & $\mathrm{~mm}$ & $\mathrm{dm}$ & & & & & \multicolumn{2}{|c|}{$\%$} \\
\hline $00-05$ & 5,2 & 1 & 34 & 23 & 13 & 2,6 & 72,6 & 48 & 24 & 53 & 2,5 \\
\hline $05-10$ & 4,5 & 6 & 52 & 11 & 6 & 2,1 & 71,1 & 40 & 14 & 27 & 23,9 \\
\hline $10-30$ & 4,2 & 7 & 52 & 8 & 4 & 1,4 & 65,4 & 27 & 13 & 20 & 36,5 \\
\hline
\end{tabular}


TABELA 3 - Análise granulométrica do solo. Fazenda Santa Terezinha, Tibagi, PR 1997.

\begin{tabular}{cccc}
\hline \multirow{2}{*}{ Profundidade } & \multicolumn{3}{c}{$\%$} \\
\cline { 2 - 4 } & Areia & Silte & Argila \\
\hline $00-05$ & 36 & 34 & 30 \\
$05-10$ & 30 & 28 & 42 \\
$10-30$ & 30 & 24 & 46 \\
\hline
\end{tabular}

TABELA 4 - Análise granulométrica do solo, Fazenda Estiva, Tibagi, PR 1998.

\begin{tabular}{cccc}
\hline \multirow{2}{*}{ Profundidade } & \multicolumn{2}{c}{$\%$} & Argila \\
\cline { 2 - 4 } & Areia & Silte & 16 \\
$00-05$ & 77 & 7 & 19 \\
$05-10$ & 76 & 5 & 19 \\
$10-30$ & 74 & 7 & \\
\hline
\end{tabular}

TABELA 5 - Estádios de desenvolvimento da cultura do feijoeiro.

\begin{tabular}{cl}
\hline Estádios & \\
\hline $\mathrm{V}_{0}$ & Germinação \\
$\mathrm{V}_{1}$ & Emergêncição \\
$\mathrm{V}_{2}$ & Folhas primárias abertas \\
$\mathrm{V}_{3}$ & Primeira folha trifoliada aberta e plana \\
$\mathrm{V}_{4}$ & Terceira folha trifoliada aberta e plana \\
$\mathrm{R}_{5}$ & Primeiro rácimo floral nos nós inferiores pré-floração \\
$\mathrm{R}_{6}$ & Primeira flor aberta - floração \\
$\mathrm{R}_{7}$ & Primeira vagem \\
$\mathrm{R}_{8}$ & Plantas iniciam o enchimento da primeira vagem - enchimento de vagens \\
$\mathrm{R}_{9}$ & Maturação
\end{tabular}

${ }^{1}$ A caracterização do estádio é definida quando $50 \%$ ou mais plantas da parcela ou amostra apresentam as características descritas (5).

\section{RESULTADOS E DISCUSSÃO}

Durante o ciclo da cultura do feijão o clima pode ser considerado como típico para a região nos dois anos (1997/98 e 1998/99) e adequado à cultura [20]. Os resultados obtidos em laboratório não evidenciaram diferença significativa no teor do elemento no tecido foliar (Tabela 7 e 9). Estes teores estão interpretados como dentro da faixa considerada adequada para uma boa nutrição [15], visto que a faixa satisfatória situa-se em $20-24 \mathrm{~g} \cdot \mathrm{kg}^{-1}$. Para o rendimento, a cultura não respondeu à aplicação de potássio em diferentes doses e formas de aplicação nos dois experimentos (Tabela 8). Esses dados seguem a mesma tendência dos ensaios conduzidos em sistema de plantio convencional por Malavolta, [10]; Igue, [7]; Souza, [19]; Parra et al., [13] e Silveira e Damasceno, [18].

O potássio presente nos primeiros $10 \mathrm{~cm}$ de solo (Tabelas 1 e 2 ) foi capaz de suprir as necessidades da cultura e fez com que não houvesse resposta às diferentes doses e formas de aplicação. Porém, do total absorvido pelas plantas uma porcentagem é exportada pelas sementes e segundo Pauletti [14], essa exportação pode ser de $15,4 \mathrm{~kg}$ de $\mathrm{K}_{2} \mathrm{O}$ por tonelada de sementes. Portanto, para evitar o esgotamento dos solos com o tempo deve-se estudar com maior detalhamento o sistema de rotação de culturas usado pelo agricultor, balanço de nutrientes, tipo de solo, condições climáticas e taxa de mineralização da matéria orgânica. Dessa forma, as futuras pesquisas com adubação potássica para o feijoeiro deverão ser direcionadas para o sistema produtivo e não visando especificamente uma cultura isolada. Analisando os componentes de rendimento conforme demonstram as Tabelas 6 e 8, o número médio de vagens por planta (NMVP) não mostrou diferença significativa para as doses e formas de aplicação de potássio para os dois ensaios, contrariando os resultados obtidos por Silveira e Damasceno [18], que observaram um maior NMVP, quando foi aplicado $120 \mathrm{~kg}^{\mathrm{ha}} \mathrm{ha}^{-1} \mathrm{de}$ $\mathrm{K}_{2} \mathrm{O}$ sem parcelamento. 
SGUARIO-JR, J.C. et al. Doses e formas de aplicação...

TABELA 6 - Doses e formas de aplicação de potássio sobre o rendimento e seus componentes, população final de plantas e comprimento médio do caule. Fazenda Santa Terezinha, Tibagi, PR, 1997/98.

\begin{tabular}{|c|c|c|c|c|c|c|c|}
\hline Forma & Dose & $\begin{array}{c}\text { Rendimento } \\
\left(\mathrm{kg} \cdot \mathrm{ha}^{-1}\right)\end{array}$ & $\begin{array}{c}\text { N.․Médio } \\
\text { Vagens/Planta }\end{array}$ & $\begin{array}{c}\text { N. Médio } \\
\text { Sem./vagens }\end{array}$ & $\begin{array}{c}\text { Massa } \\
\text { Média de } \\
100 \text { sem. (g) }\end{array}$ & $\begin{array}{l}\text { Comp. } \\
\text { Médio do } \\
\text { Caule }(\mathrm{m})\end{array}$ & $\begin{array}{l}\text { Pop. Final } \\
\left(\mathrm{pl} / \mathrm{m}^{2}\right)\end{array}$ \\
\hline \multirow{5}{*}{ Linha } & 0 & 2975 a & $14,7 \mathrm{a}$ & $4,80 \mathrm{a}$ & $24,87 \mathrm{a}$ & $1,07 \mathrm{a}$ & $28,92 \mathrm{a}$ \\
\hline & 30 & $2714 \mathrm{a}$ & $14,6 \mathrm{a}$ & $4,75 \mathrm{a}$ & $25,82 \mathrm{a}$ & $1,09 \mathrm{a}$ & $30,19 \mathrm{a}$ \\
\hline & 60 & $3006 \mathrm{a}$ & $13,5 \mathrm{a}$ & $4,77 \mathrm{a}$ & $24,08 \mathrm{a}$ & $1,15 \mathrm{a}$ & $29,14 \mathrm{a}$ \\
\hline & 90 & 2948 a & $11,3 \mathrm{a}$ & $4,70 \mathrm{a}$ & $24,32 \mathrm{a}$ & $1,15 \mathrm{a}$ & 30,96 a \\
\hline & 120 & 3085 a & $13,2 \mathrm{a}$ & $4,72 \mathrm{a}$ & $25,13 \mathrm{a}$ & $1,17 \mathrm{a}$ & 30,30 a \\
\hline \multirow{5}{*}{ Lanço } & 0 & $2975 a$ & $14,7 \mathrm{a}$ & $4,80 a b$ & $24,87 \mathrm{a}$ & $1,07 \mathrm{a}$ & $28,92 \mathrm{a}$ \\
\hline & 30 & 2917 a & $15,2 \mathrm{a}$ & $4,95 \mathrm{a}$ & $23,15 \mathrm{a}$ & $1,17 \mathrm{a}$ & $28,74 \mathrm{a}$ \\
\hline & 60 & $2843 \mathrm{a}$ & $11,5 \mathrm{a}$ & $4,77 a b$ & $25,37 \mathrm{a}$ & $1,20 \mathrm{a}$ & 28,86 a \\
\hline & 90 & $2883 \mathrm{a}$ & $10,8 \mathrm{a}$ & $4,47 \mathrm{~b}$ & $25,15 \mathrm{a}$ & $1,15 \mathrm{a}$ & $27,97 \mathrm{a}$ \\
\hline & 120 & 2983 a & $13,2 \mathrm{a}$ & $4,90 \mathrm{a}$ & $24,53 \mathrm{a}$ & $1,22 \mathrm{a}$ & 29,59 a \\
\hline CV\% & & 11,63 & 18,97 & 4,23 & 4,59 & 10,4 & 6,19 \\
\hline
\end{tabular}

Médias seguidas da mesma letra, nas colunas, não diferem significativamente pelo teste de Tukey $(P<0,05)$.

TABELA 7 - Doses e formas de aplicação de potássio sobre o acúmulo de massa seca e teor de potássio no tecido foliar, nos estádios reprodutivos $R_{5}, R_{6}, R_{7}, R_{8}$ e $R_{9}$. Fazenda Santa Terezinha, Tibagi, PR 1997/98.

\begin{tabular}{|c|c|c|c|c|c|c|c|}
\hline Forma & Dose & $M S^{*} . R_{5}(g)$ & MS. $R_{6}(g)$ & MS. $R_{7}(g)$ & MS. $R_{8}(g)$ & MS. $R_{9}(g)$ & $\begin{array}{c}\text { Teor de } \\
\text { Potássio foliar } \\
\left(\mathrm{g} \cdot \mathrm{kg}^{-1}\right)\end{array}$ \\
\hline \multirow{5}{*}{ Linha } & 0 & $62,1 \mathrm{a}$ & $109,7 \mathrm{a}$ & $128,8 \mathrm{a}$ & $168,0 \mathrm{a}$ & $271,7 \mathrm{a}$ & $24,50 \mathrm{a}$ \\
\hline & 30 & $60,1 \mathrm{a}$ & $112,4 \mathrm{a}$ & $154,1 \mathrm{a}$ & $151,4 \mathrm{a}$ & $276,7 \mathrm{a}$ & $23,10 \mathrm{a}$ \\
\hline & 60 & $60,7 \mathrm{a}$ & $113,9 a$ & $127,4 \mathrm{a}$ & $216,5 \mathrm{a}$ & $260,9 a$ & $25,10 \mathrm{a}$ \\
\hline & 90 & $55,3 \mathrm{a}$ & 108,3 a & $135,6 \mathrm{a}$ & $160,0 \mathrm{a}$ & 248,8 a & $25,55 \mathrm{a}$ \\
\hline & 120 & $56,9 \mathrm{a}$ & $111,6 \mathrm{a}$ & $126,8 \mathrm{a}$ & $161,2 \mathrm{a}$ & $250,1 \mathrm{a}$ & $23,85 a$ \\
\hline \multirow{5}{*}{ Lanço } & 0 & $62,1 \mathrm{a}$ & $109,7 \mathrm{a}$ & $128,8 \mathrm{a}$ & $168,0 \mathrm{a}$ & $271,7 \mathrm{a}$ & $24,50 \mathrm{a}$ \\
\hline & 30 & 54,7 a & $110,2 \mathrm{a}$ & $132,4 \mathrm{a}$ & $243,4 \mathrm{a}$ & $274,7 \mathrm{a}$ & $20,55 \mathrm{a}$ \\
\hline & 60 & $56,4 \mathrm{a}$ & 106,6 a & $138,6 \mathrm{a}$ & $154,0 \mathrm{a}$ & 230,6 a & $24,85 a$ \\
\hline & 90 & $53,1 \mathrm{a}$ & $113,2 \mathrm{a}$ & $123,1 \mathrm{a}$ & 205,2 a & 209,0 a & $24,00 \mathrm{a}$ \\
\hline & 120 & $54,1 \mathrm{a}$ & $113,1 \mathrm{a}$ & $134,9 \mathrm{a}$ & $168,7 \mathrm{a}$ & $263,8 \mathrm{a}$ & $23,40 \mathrm{a}$ \\
\hline CV\% & & 8,17 & 5,2 & 15,56 & 14,57 & 15,84 & 15,32 \\
\hline
\end{tabular}

Médias seguidas da mesma letra, nas colunas, não diferem significativamente pelo teste de Tukey $(P<0,05)$.

*MS: massa seca de plantas nos referidos estádios reprodutivos.

Para o número médio de sementes por vagens (NMSV) não foi observado diferença entre os tratamentos (Tabela 8). Entretanto, para o experimento de 1997/98 (Tabela 6) na dose de 90 kg.ha-1 de $\mathrm{K}_{2} \mathrm{O}$ e com aplicação a lanço, houve diferença significativa causando redução em 9,7\% em relação ao maior valor que foi obtido com a dose $30 \mathrm{~kg} \cdot \mathrm{ha}^{-1}$ de $\mathrm{K}_{2} \mathrm{O}$. A massa média de 100 sementes (MM100S) também não respondeu aos diferentes tratamentos e os valores obtidos ficaram similares entre eles, mostrando assim, pouca variação nesse componente de rendimento [3].

Com relação à população final de plantas (Tabela 8), não houve diferença entre os tratamentos, diferente do encontrado por Kluthcouski, [9], que concluiu que doses maiores que 30 - $40 \mathrm{~kg} \cdot \mathrm{ha}^{-1}$ de $\mathrm{K}_{2} \mathrm{O}$ devem ser aplicadas somente como complementação à lanço, após a emergência das plantas para evitar redução na população final de plantas pelo efeito salino. Com a colocação do $\mathrm{K}_{2} \mathrm{O}$ à $5 \mathrm{~cm}$ ao lado e abaixo das sementes não ocorreu redução da população de plantas. Para o comprimento do caule não foram identificados diferenças entre os tratamentos (Tabela 6), chegando a resultados similares aos observadas por Almeida e Sangoi [1]. Estes autores relataram que em plantios tardios a população deve ser aumentada e se preciso o espaçamento entre linhas reduzido, em função do menor crescimento das plantas para haver incremento da produtividade. 
SGUARIO-JR, J.C. et al. Doses e formas de aplicação...

TABELA 8 -Doses e formas de aplicação de potássio sobre o rendimento, componentes de rendimento, população final de plantas e comprimento médio do caule. Fazenda Estiva, Tibagi, PR, 1998/99.

\begin{tabular}{|c|c|c|c|c|c|c|c|}
\hline Forma & Dose & $\begin{array}{c}\text { Rendimento } \\
\left(\mathrm{kg} \cdot \mathrm{ha}^{-1}\right)\end{array}$ & $\begin{array}{c}\text { N. Médio } \\
\text { Vagens/Pla } \\
\text { nta }\end{array}$ & $\begin{array}{c}\text { N.․ Médio } \\
\text { Sem./vagens }\end{array}$ & $\begin{array}{l}\text { Massa Média } \\
\text { de } 100 \text { sem. } \\
\text { (g) }\end{array}$ & $\begin{array}{l}\text { Comp. } \\
\text { Médio do } \\
\text { Caule (m) }\end{array}$ & $\begin{array}{l}\text { Pop. Final } \\
\left(\mathrm{pl} / \mathrm{m}^{2}\right)\end{array}$ \\
\hline \multirow{5}{*}{ Linha } & 0 & $2879 a$ & $11,6 \mathrm{a}$ & $5,05 a$ & $25,12 \mathrm{a}$ & $0,75 a$ & $18,39 a$ \\
\hline & 30 & $2639 a$ & $10,9 a$ & $5,12 a$ & $25,03 \mathrm{a}$ & $0,65 a$ & $18,89 a$ \\
\hline & 60 & $2615 \mathrm{a}$ & $9,6 \mathrm{a}$ & $5,34 \mathrm{a}$ & $25,55 \mathrm{a}$ & $0,72 \mathrm{a}$ & $18,52 \mathrm{a}$ \\
\hline & 90 & $2720 \mathrm{a}$ & $14,4 \mathrm{a}$ & $5,10 a$ & $25,56 \mathrm{a}$ & $0,82 \mathrm{a}$ & $19,42 \mathrm{a}$ \\
\hline & 120 & 2837 a & $9,6 \mathrm{a}$ & $5,20 \mathrm{a}$ & $25,44 \mathrm{a}$ & $0,75 a$ & $19,64 \mathrm{a}$ \\
\hline \multirow{5}{*}{ Lanço } & 0 & $2879 \mathrm{a}$ & $11,6 \mathrm{a}$ & $5,05 a$ & $25,12 \mathrm{a}$ & $0,75 a$ & $18,39 \mathrm{a}$ \\
\hline & 30 & $2625 \mathrm{a}$ & $9,5 \mathrm{a}$ & $5,02 \mathrm{a}$ & $24,94 \mathrm{a}$ & $0,72 \mathrm{a}$ & $18,53 \mathrm{a}$ \\
\hline & 60 & $2609 a$ & $9,5 \mathrm{a}$ & $5,17 \mathrm{a}$ & $25,36 \mathrm{a}$ & $0,80 a$ & $19,03 \mathrm{a}$ \\
\hline & 90 & $2653 \mathrm{a}$ & $11,2 \mathrm{a}$ & $5,22 \mathrm{a}$ & $24,27 \mathrm{a}$ & $0,72 \mathrm{a}$ & $19,94 \mathrm{a}$ \\
\hline & 120 & $2788 a$ & $10,7 \mathrm{a}$ & $5,35 a$ & $23,11 \mathrm{a}$ & $0,70 \mathrm{a}$ & $19,19 \mathrm{a}$ \\
\hline CV\% & & $-9,45$ & 13,74 & 4,38 & 5,07 & 14,72 & 15,9 \\
\hline
\end{tabular}

Médias seguidas da mesma letra, nas colunas, não diferem significativamente pelo teste de Tukey $(P<0,05)$.

TABELA 9 - Doses e formas de aplicação de potássio sobre o acúmulo de massa seca e teor de potássio no tecido foliar, nos estádios reprodutivos $R_{5}, R_{6}, R_{7}, R_{8}$ e $R_{9}$. Fazenda Estiva, Tibagi, PR 1998/99.

\begin{tabular}{|c|c|c|c|c|c|c|c|}
\hline Forma & Dose & $M S^{*} . R_{5}(g)$ & MS. R6 $(g)$ & MS. $R_{7}(g)$ & MS. $R_{8}(g)$ & MS. R9 (g) & $\begin{array}{c}\text { Teor de } \\
\text { Potássio foliar } \\
\left(\mathrm{g} \cdot \mathrm{kg}^{-1}\right)\end{array}$ \\
\hline \multirow{5}{*}{ Linha } & 0 & $34,4 \mathrm{a}$ & $54,8 \mathrm{a}$ & $93,8 \mathrm{a}$ & $181,7 \mathrm{a}$ & $243,1 \mathrm{a}$ & $27,80 \mathrm{a}$ \\
\hline & 30 & $37,6 \mathrm{a}$ & 55,9 a & $93,8 \mathrm{a}$ & $166,7 \mathrm{a}$ & $237,8 \mathrm{a}$ & $26,70 \mathrm{a}$ \\
\hline & 60 & $37,4 \mathrm{a}$ & $52,3 \mathrm{a}$ & $95,0 \mathrm{a}$ & $155,5 \mathrm{a}$ & $252,6 \mathrm{a}$ & $26,10 \mathrm{a}$ \\
\hline & 90 & $36,9 a$ & $59,2 \mathrm{a}$ & $85,2 \mathrm{a}$ & 204,6 a & 239,3 a & $26,20 \mathrm{a}$ \\
\hline & 120 & $36,7 \mathrm{a}$ & $66,5 \mathrm{a}$ & $77,5 \mathrm{a}$ & $216,8 \mathrm{a}$ & $260,4 a$ & $27,45 \mathrm{a}$ \\
\hline \multirow{5}{*}{ Lanço } & 0 & $34,4 \mathrm{a}$ & $54,8 \mathrm{a}$ & $93,8 \mathrm{a}$ & $181,7 \mathrm{a}$ & $243,1 \mathrm{a}$ & $27,80 \mathrm{a}$ \\
\hline & 30 & $39,6 \mathrm{a}$ & $69,3 \mathrm{a}$ & $89,6 \mathrm{a}$ & $189,9 \mathrm{a}$ & $263,7 \mathrm{a}$ & $26,80 \mathrm{a}$ \\
\hline & 60 & $36,6 \mathrm{a}$ & $62,5 \mathrm{a}$ & $78,9 \mathrm{a}$ & $166,9 \mathrm{a}$ & $257,7 \mathrm{a}$ & $26,10 \mathrm{a}$ \\
\hline & 90 & $35,1 \mathrm{a}$ & $52,0 \mathrm{a}$ & $77,8 \mathrm{a}$ & $210,1 \mathrm{a}$ & $262,7 \mathrm{a}$ & $26,40 \mathrm{a}$ \\
\hline & 120 & 35,9 a & $64,8 \mathrm{a}$ & 101,9 a & $196,5 \mathrm{a}$ & $270,3 \mathrm{a}$ & $27,20 \mathrm{a}$ \\
\hline CV\% & & 10,55 & 18,77 & 21,01 & 21,07 & 6,73 & 6,19 \\
\hline
\end{tabular}

Médias seguidas da mesma letra, nas colunas, não diferem significativamente pelo teste de Tukey $(P<0,05)$.

${ }^{*}$ MS: massa seca de plantas nos referidos estádios reprodutivos.

\section{CONCLUSÕES}

A cultivar Carioca cultivado no sistema de plantio direto não apresentou resposta de rendimento e seus componentes para as diferentes doses e formas de aplicação de potássio nas safras de 1997/98 e 1998/99.

O crescimento e a população de plantas não foram influenciados pelas diferentes doses e formas de aplicação de potássio, nas condições do experimento. 


\section{REFERÊNCIAS}

1. ALMEIDA, M. L., SAMGOI, L. Manejo de cultivares de feijão de diferentes hábitos de crescimento no plantio catarinense. I rendimento de grãos. Ciência Rural, Santa Maria, v.24, n.3, p. 513-514, 1994.

2. ALMEIDA, L. J.; LEITÃO FILHO, H. ; MIYASAKA, S. Características do feijão carioca, um novo cultivar. Bragantia, Campinas, v.30, p. 33-38, 1977

3. ARF, O; BUZETTI, S.; SÁ, M. E.; TOLEDO, A. R. M.; OLIVEIRA, C. A. G.; FUJIWARA, O. R. H.; ROMERO, P. J. M.; GUERREIRO NETO, G. Efeito de diferentes espaçamentos e densidades sobre os componentes produtivos do feijoeiro (Phaseolus vulgaris $L$.) adubado em função da área e do espaçamento entre linhas. Cultura Agronômica, llha Solteira, v.1, n.1, p. 1-10, 1992.

4. BARAMPAMA, Z. ; SIMARD, R. E. Nutrient composition, protein quality and antinutritional factors of some varieties of dry beans. (Phaseolus vulgaris I.) grown in burundi. Food Chemistry, v. 47, p. 159-67, 1993.

5. FERNANDES, F.; GEPTS.; LOPES, M. Etapas de Deserollo de La Planta de Frijol. In. FRIJOL: INVESTIGACION E PRODUCION. CALI, Colombia: PNUO/CIAT, p. 418,1985.

6. HAN, V. D. B. Avaliação Econômica $97 / 98$ e Orçamento para a Safra 99/00. Informativo Fundação ABC para Assistência Técnica Agropecuária, Castro, n.3, p.23-25, 1999.

7. IGUE, T. Interações em grupos de experimentos de adubação do feijoeiro com N, P e K, seguindo o esquema fatorial 3×3x3. Piracicaba, 1968. Dissertação-ESALQ.

8. KOEHLER, H. S. Estatística Experimental. Curitiba. Universidade Federal do Paraná, 1998. 124 p.

9. KLUTHCOUSKI, J. Efeito salino, causado por fertilizantes, no sistema de plantio direto sobre as culturas do feijão, soja e arroz. In: REUNIÃO NACIONAL DE PESQUISA DE FEIJÃO (1999: Salvador). Resumos. Salvador: Embrapa Arroz e Feijão, 1999. p.797800.

10. MALAVOLTA, E. Nutrição e adubação. In: SIMPÓSIO BRASILEIRO DE FEIJÃO, 1972. Resumos. Viçosa, 1972. p. 209 - 242.

11. MUZILLI, O. Plantio direto no Paraná: princípio e perspectivas de expansão. Londrina : IAPAR, 1981.p.11-17. (Circular 23).

12. MUZILLI, O. Influência do sistema de plantio direto, comparado ao convencional sobre a fertilidade da camada arável do solo. Revista Brasileira de Ciência do Solo. Campinas, v. 7, p. 95-102, 1983.

13. PARRA, M. S. Nutrição e Adubação . In: IAPAR. O Feijão no Paraná. Londrina: IAPAR, 1989. p. 79-100.

14. PAULETTI, V. Nutrientes teores e interpretações. Informativo Fundação ABC/Fundação Cargill, Campinas, n. 219, p.8-11, 1998.

15. RAIJ, B. Van; CATARELLA, H.; QUAGGIO, J. A.; FURLANI, A. M. C. Recomendações de adubação e calagem para o estado de São Paulo. 2.ed. Campinas: Instituto Agronômico e fundação IAC, 1996. 285 p.

16. SÁ, J. C. M. Manejo da fertilidade do solo no plantio direto. Castro: Fundação ABC, 1993. 96 p.

17. SIDIRAS, N.; PAVAN, M. A. Influência do sistema de manejo do solo no seu nível de fertilidade. Revista Brasileira de Ciência Solo, Campinas, v. 9, p. 249-254, 1985.

18. SILVEIRA, P. M.; DAMASCENO, M. A. Doses e Parcelamento de K e N na Cultura do Feijoeiro Irrigado. Pesquisa Agropecuária Brasileira, Brasília, v. 28, n. 11, p. 1269-1276, 1993.

19. SOUZA, T. S. Nutrição e adubação em feijoeiro. Datil, 1971.

20. VIEIRA, C. Cultura do feijão. Viçosa : UFV. Imprensa Universitária, 1978. 146p.

Recebido em 06/07/2001

Aceito em 31/07/2006 